\title{
Biodiversity of Rhizobia That Nodulate Melilotus indicus L. in Egyptian Soils
}

\author{
Nadia H. El-Batanony, Ayat M. Bdwy* , H.E. Hassan * \\ and M.E. El-Lithy ${ }^{* \#}$ \\ Environmental Studies \& Research Institute (ESRI), University of \\ Sadat City, Sadat City and *Botany Department, Faculty of \\ Science, Menoufia University, Shebin El-Kom, Menoufia, Egypt.
}

\begin{abstract}
7 HE OBJECTIVES of this work were to describe the biodiversity and the phylogeny of the selected rhizobial isolates nodulating wild legume Melilotus indicus L. (M. indicus) from 14 different Egyptian soils. These isolates were characterized morphologically and physiologically on the basis of their tolerance to $\mathrm{NaCl}$ and $\mathrm{pH}$. Furthermore, the DNA of each rhizobial isolate was analyzed by repPCR amplification fingerprinting using REP, ERIC and BOX A1R primers. Thirty seven rhizobial isolates were obtained from the root nodules of $M$. indicus. These isolates didn`t absorb Congo- red (CR) when incubated in dark; grew poorly, or not at all, on peptone glucose agar medium containing bromocresol purple (BCP) and acidified the medium suggesting fast-growing rhizobia. Five isolates tolerated $\mathrm{NaCl}$ up to $7 \%$. Rhizobial isolates showed a wide diversity in their $\mathrm{pH}$ tolerance. Moreover, PCR with REP and ERIC primer pairs yielded multiple distinct DNA products for each isolate of size ranged from approximately 177 to $3773 \mathrm{bp}$ and 200 to $2921 \mathrm{bp}$, respectively. BOX A1R primer did not reveal any polymorphism for the isolates. We can conclude that rhizobia isolated from M. indicus from Egyptian soils are both phenotypically and genetically diverse.
\end{abstract}

Keywords: Genetic Diversity, Legume Nodules, Melilotus, Rhizobia.

In fact, rhizobial distribution and survival in natural habitats are due to the impact of the environmental factors prevailing in such habitats and the existence of the proper host. Also, the existence of diverse rhizobia helps the host legumes to be adapted to many different habitats (Bala \& Giller, 2006). While, the great diversity and the vast geographic distribution of the legumes shaped their distinct rhizobial populations and drove their diversification (Drew \& Ballard, 2010). Therefore, the diversity of rhizobia present in certain ecosystems is a result of interactions between rhizobia, their host legumes, biotic and abiotic factors of the ecosystem (Yan et al., 2014).

In the Rhizobium-legume symbiosis, the process of $\mathrm{N}_{2}$ fixation is strongly related to the physiological status of the host plant. Therefore, competitiveness and persistence of rhizobial strains are not expected to be expressed in full

\footnotetext{
\# Corresponding author: email: m_ellithy@yahoo.com

Tel.: +2 01007500881,

Fax: +2 0482235689 ,
} 
capacity for nitrogen fixation if restrictive factors, such as salinity, unfavorable soil $\mathrm{pH}$, impose limitations on vigor and growth of the host legume. A given stress may also have more than one effect: e.g., salinity may act as a water stress, which affects photosynthetic rate, or may affect nodule metabolism directly (Zahran, 1999). Such stresses suppress growth and symbiotic power of most rhizobia (Gálvez, 2005).

The different responses of rhizobial strains to stress factors could be considered as basic criteria for differentiation and identification of these bacteria (Zahran et al., 2012). Regarding rhizobia, soil $\mathrm{pH}$ and salinity are the main ecological factors determining their diversity (Adhikari et al., 2012). It is expected that the genetic variation for traits in nature reflect their adaptation to specific environments (Koornneef et al., 2004).

Studying rhizobial biodiversity enables isolation of an effective isolates from wild legumes that could be used in reforestation programs. Also, it's a good strategy to improve quality and productivity of leguminous crops (food and feed) when inoculated with such isolates (Zahran et al., 2012). Rhizobia of wild legumes may have better traits such as phosphorous solublization, producing plant growth promoting (PGP) compounds as indole acetic acid (IAA) and/or hydrogen cyanide $(\mathrm{HCN})$ and/or possessing antibiosis effect (Alikhania \& Yakhchali, 2009 and Arora et al., 2001). Also, being tolerant to different stressful conditions more than the specific rhizobia of the cultivated leguminous crops (Abdel-Salam et al., 2010 and Zahran et al., 2012). Such bacteria are very important from both economical and environmental points of view (Kesari et al., 2013).

Several molecular techniques have been readily developed to examine rhizobial biodiversity. These include: RAPD-PCR (random amplified polymorphic DNA-polymerase chain reaction), PCR amplification of REP (repetitive extragenic palindrome), ERIC (enterobacterial repetitive intergeneric consensus) and BOX element or RFLP (random amplified length polymorphism) of amplified ribosomal genes (16S, $23 \mathrm{~S}$ or $16 \mathrm{~S}-23 \mathrm{~S}$ inter generic spacer - IGS), and nod or nif genes sequencing (De Bruijn, 1992; Edulamudi et al., 2015; Laguerre et al., 1994 and Versalovic et al., 1994). Also, amplified ribosomal DNA restriction analysis (ARDRA) of both $16 \mathrm{~S}$ and 23S rDNA (Shamseldin et al., 2005) have been used to study the variation that exist for rhizobial isolates.

In Egypt, wild legumes, such as $M$. indicus plants, are widely distributed through the Mediterranean costal region, the Nil Delta and the deserts where there is a remarkable diversity of such plant species. M. indicus, sometimes incorrectly written $M$. indica, is a yellow-flowered herb native to northern Africa, Europe and Asia, as forage and as a soil improver (Velázquez et al., 2010). Nevertheless, little information is known about the diversity of the endophytic rhizobia associated with $M$. indicus plants and their importance to legume establishment and growth.

Egypt. J. Microbiol. 50 (2015) 
Accordingly, the present work aimed to describe the biodiversity and the phylogeny of endophytic rhizobia nodulating wild legume $M$. indicus from 14 different Egyptian soils.

\section{Material and Methods}

Plant sampling and nodules collection

Fourteen locations were selected to study endophytic rhizobial diversity that exists in root nodules of $M$. indicus (L.) All. These locations were pinpointed by GPS (Magellan GPS 310), which distributed from East to West Mediterranean sea coast and within Nile Delta, (Table 1). Plants were sampled at the flowering and/or fruiting stage from the 14 locations. The collected plants were identified according to Täckholm (1974) and Boulos (2000). Nodules were collected and preserved according to Somasegaran \& Hoben (1994).

TABLE 1. Locations of the collected plants, date of collection, latitude, longitude, and isolates number (no)/location. Alex=Alexandria.

\begin{tabular}{|c|c|c|c|c|c|}
\hline No & Locations & Date & Latitude & Longitude & Isolates no/ location \\
\hline 1 & Abo Shnar & $1 / 4 / 2014$ & N 311701 & E 340994 & $1.2,1.2^{*}$ \\
\hline 2 & Rafah & $1 / 4 / 2014$ & N 310867 & E 335158 & $8.1,8.7$ \\
\hline 3 & Arish & $1 / 4 / 2014$ & N 305412 & E 322409 & $9.1,9.17,9.19$ \\
\hline 4 & Port Said & $31 / 3 / 2014$ & N 304227 & E 321612 & $4.8,4.17,4.21$ \\
\hline 5 & Ismailia & $13 / 4 / 2014$ & N 303149 & E 320949 & $11.1,11.2$ \\
\hline 6 & Ismailia & $31 / 3 / 2014$ & N 302986 & E 320713 & $3.6,3.12 *$ \\
\hline 7 & Kafr Al-Shaykh & $19 / 4 / 2014$ & N 310501 & E 305742 & $13.1,13.2$ \\
\hline 8 & Rasheed & $19 / 4 / 2014$ & N 312219 & E 302457 & $16.3,16.4$ \\
\hline 9 & 40Km West Alex & $20 / 4 / 2014$ & N 305539 & E 292809 & $14.1,14.2,15.1,15.2$ \\
\hline 10 & 55Km West Alex & $14 / 4 / 2014$ & N 305459 & E 292652 & 6.2 \\
\hline 11 & El Dabaa & $14 / 4 / 2014$ & N 310057 & E 283346 & $7.1,7.9$ \\
\hline 12 & $\begin{array}{c}\text { Shebeen El-Kom } \\
\text { (Unifarm) }\end{array}$ & $4 / 4 / 2014$ & N 305577 & E 310174 & $10.1,10.11$ \\
\hline 13 & $\begin{array}{l}\text { El Sadat City } \\
\text { (Unifarm) }\end{array}$ & $7 / 3 / 2014$ & N 302307 & E 303055 & $12.1,12.2,12.3,12.4$ \\
\hline 14 & Faiyum (Tamya) & $25 / 4 / 2014$ & N 292907 & E 305440 & $2.2,2.15,2.36,2.4,2.7,2.8$ \\
\hline
\end{tabular}

Isolation and purification of rhizobia from nodules

Endophytic bacteria were isolated from root nodules according to Vincent (1970) onto yeast extract mannitol agar (YEMA) containing Congo red (CR). The well purified single colony was streaked onto peptone glucose agar plates containing bromocresol purple $(B C P)$ to confirm rhizobial selection. Well isolated colonies were re-streaked onto YEMA for better purification then single colony was selected and streaked on YEMA slants containing $1 \mathrm{~g}$ calcium carbonate per liter then stored at $4^{\circ} \mathrm{C}$. 


\section{Growth characterization of rhizobial isolates}

The morphological traits (Elevation, margin, transparency, color, diameter and texture) and the production of acid or alkali were recorded by growing the isolates respectively on YEMA supplemented with CR and on YEMA supplemented with Bromothymol blue (BTB) (Somasegaran \& Hoben, 1994 and Shetta et al., 2011). Gram-stain reaction of the different rhizobial isolates and cell morphology were examined (Vincent, 1970).

Physiological characterization of rhizobial isolates

Several experiments were performed in broth tubes or agar plates inoculated with an exponentially growing liquid culture. All the experiments were carried out in triplicate otherwise it will be indicated. Bacterial growth was quantified as 0 (no growth), 1 (low growth), 2 (medium growth) or 3 (high growth = the control) otherwise it will be specified.

\section{$\mathrm{NaCl}$ tolerance}

Rhizobial isolates were grown on YEM broth at different concentrations of $\mathrm{NaCl}$ ranged from 1 to $7 \%(\mathrm{w} / \mathrm{v})$ to test their salt tolerance. Growth was determined after $72 \mathrm{~h}$ of incubation at $28-30^{\circ} \mathrm{C}$ by measuring the turbidity at 550nm using spectrophotometer (Metertek SP-850) (Singh et al., 2008).

\section{pH tolerance}

The ability of isolates to grow in acidic or alkaline media was determined on YEMA Petri dishes, where $\mathrm{pH}$ was adjusted either to 4, 5, 6, 9, 10 or 11 . Bacterial growth was recorded (from 0 to 3 ), after 4 days of incubation at 28$30^{\circ} \mathrm{C}$, compared to the control that was adjusted to pH 6.8 (Beauregard et al., 2004).

\section{Molecular characterization of rhizobial isolates}

DNA isolation and gel electrophoresis

DNA was isolated from rhizobial cells either grown on solid or liquid media. The Stewart \& Via (1993) DNA isolation protocol adopted originally for plant tissues was adapted in this work for rapid extraction of small quantities DNA. The concentration and purity of DNA were estimated spectrophotometrically at 260 and $280 \mathrm{~nm}$, respectively.

PCR amplification with REP and ERIC primers

REP and ERIC fingerprinting were performed with primers REP 1R-I and REP 2-I and ERIC 1R and ERIC 2, respectively (De Bruijn, 1992). The PCR reactions for REP and ERIC primers were carried out in $25 \mu$ l volume with the following modifications: $1 \mu \mathrm{l}$ of each two opposing primers $(50 \mathrm{pmol} / \mu \mathrm{l})$ (Metabion international AG, Germany); $0.4 \mu \mathrm{l}$ of $50 \mathrm{mM}$ dNTP Mix (AllianceBio); $2.5 \mu \mathrm{l}$ polymerase reaction buffer $(10 \mathrm{x})$ "complete": $160 \mathrm{mM}$ $\left(\mathrm{NH}_{4}\right)_{2} \mathrm{SO}_{4}, 670 \mathrm{mM}$ Tris- $\mathrm{HCl} \mathrm{pH}$ 8.8, $0.1 \%$ Tween-20, $25 \mathrm{mM} \mathrm{MgCl}$ (BIORON GmbH); $0.8 \mu \mathrm{l}(5 \mathrm{U} / \mu \mathrm{l})$ Taq DNA polymerase (BIORON GmbH); $1.5 \mu \mathrm{l}$ of DNA $50 \mathrm{ng} / \mu \mathrm{l}$ and finally sterile milli-Q water to complete the volume.

Egypt. J. Microbiol. 50 (2015) 
The cycles used were as follows: 1 cycle at $95^{\circ} \mathrm{C}$ for 6 or $7 \mathrm{~min}, 30$ cycles at $94^{\circ} \mathrm{C}$ for $1 \mathrm{~min}$, at 40 or $52^{\circ} \mathrm{C}$ for $1 \mathrm{~min}$, and at $65^{\circ} \mathrm{C}$ for $8 \mathrm{~min} ; 1$ cycle at $65^{\circ} \mathrm{C}$ for $16 \mathrm{~min}$; and a final soaking at $4^{\circ} \mathrm{C}$, for REP or ERIC primers, respectively.

PCR amplification with specific BOX AlR primer

The DNA of each bacterium was amplified by PCR with primer BOX A1R as described by Kaschuk et al. (2006).

DNA and the amplified fragments were separated on $1 \%$ agarose gel (BIO-RAD) at $85 \mathrm{~V}$ for $3 \mathrm{~h}$. GeneRuler ${ }^{\mathrm{TM}} 1 \mathrm{~Kb}$ Plus DNA Ladder, ready-touse, (Fermentas) was used as molecular marker. All the PCR reactions were carried out in an TC-96/T/H(a) BIOER TECHNOLOGY CO., LTD, thermal cycler and the amplified fragments were separated by horizontal electrophoresis SGE-020-02, C.B.S.*SCIENTIFIC $(20 \mathrm{~cm} * 20 \mathrm{~cm})$. Gels were stained with ethidium bromide, visualized under UV light (UVP, PhotoDoc-It, ${ }^{\mathrm{TM}}$ Imaging System Digital, UK) and photographed with a Canon Power Shot A720 IS camera. The gel photos were analyzed using UVI soft UVI band map windows Application Vll.1l.

\section{Results}

\section{Isolation and purification of rhizobia from nodules}

A total of 37 rhizobial pure isolates were selected from the endophytic bacteria that exist in the root nodules of $M$. indicus plants. They showed little or no CR absorption when incubated in dark. The rhizobial isolates grow poorly, or not at all, on peptone glucose agar medium containing BCP, heavy growth is indicative of contamination (Somasegaran \& Hoben, 1994).

\section{Growth characterization of rhizobial isolates}

The colony shape of the obtained 37 isolates was either dome (30 isolates) or flat (seven isolates). The colonies were round with smooth edges. Thirty two isolates were opaque while five isolates were translucent. Colony color was milky (27 isolates), white (4 isolates), yellow ( 2 isolates) or watery (4 isolates) while colony size ranged from $0.1 \mathrm{~cm}$ to $0.7 \mathrm{~cm}$ in diameter. The texture varied from being not sticky ( 8 isolates), semi sticky ( 2 isolates) to sticky ( 27 isolates) colonies.

The green color of agar media (YEMA containing BTB) changed to yellow color as all the selected isolates acidified the medium assuming fast-growing rhizobia.

All the isolates were gram-negative being short rod in shape with pink color under light microscope.

\section{Physiological characterization of rhizobial isolates}

A number of experiments were carried out in order to characterize the rhizobia isolated from root nodules of Melilotus indicus (L.) physiologically. Such experiments will be used for further clustering to discriminate between the rhizobial isolates for their similarities as well as their natural variation. 


\section{$\mathrm{NaCl}$ tolerance}

All isolates grew in the control cultures $\left(28-30^{\circ} \mathrm{C}, \mathrm{pH} 6.8\right.$ and $\left.0.01 \% \mathrm{NaCl}\right)$. Fig. 1 showed the frequency distribution of the rhizobial isolates grew at different $\mathrm{NaCl}$ concentrations. Most of the isolates were able to grow and showed good salt tolerance efficiency up to $3 \% \mathrm{w} / \mathrm{v} \mathrm{NaCl}$. While, $81 \%, 70.2 \%$ and $32.4 \%$ of the isolates could grow up to $4 \%, 5 \%$ and $6 \% \mathrm{NaCl}$, respectively. Isolates 9.1 , $9.17,10.11,15.1$ and 15.2 were able to tolerate a maximum concentration up to $7 \% \mathrm{NaCl}$
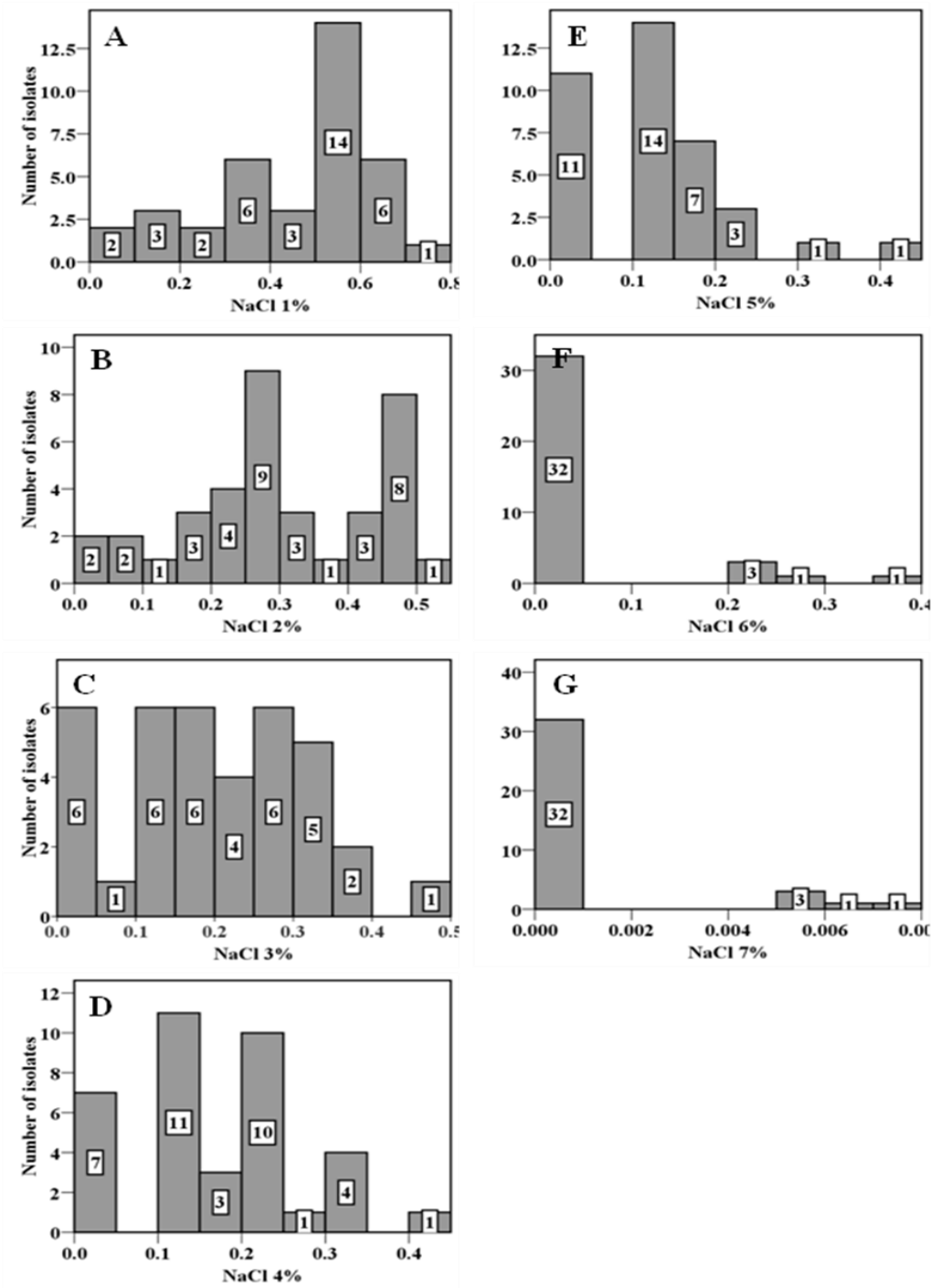

Fig. 1. Frequency distribution of the different isolates showing the effect of different NaCl concentrations.

Egypt. J. Microbiol. 50 (2015) 
When analyzed separately, the dendrogram obtained from numerical analysis of the isolates according to their tolerance to different $\mathrm{NaCl}$ concentrations showed a wide diversity among them (Fig. 2). All the isolates were placed in two distinctive major groups (group I and II). Group I differentiated into two subgroups; subgroup 1 include isolates $(12.1,12.2,7.9,12.4$ and 7.1$)$, that were able to grow and tolerate $\mathrm{NaCl}$ concentration up to $3 \%$ and few of them had the same origin. While, subgroup 2 include isolates (13.1, 14.2, 8.1, 13.2 and 12.3) that were able to grow and tolerate $\mathrm{NaCl}$ concentration from $3 \%$ to $5 \%$ and few of them had the same origin. Group II separated to two faraway subgroups; subgroup 1 and subgroup 2. The latter was divided into many subgroups, where isolate 6.2 was the most deviating one. Also, in this subgroup 2, isolates $(2.7,2.8$, $2.15,2.36,2.2,2.4$ and 4.8$)$ were closely clustered. Such isolates were able to grow and tolerate $\mathrm{NaCl}$ concentration up to $6 \%$ and had the same origin.

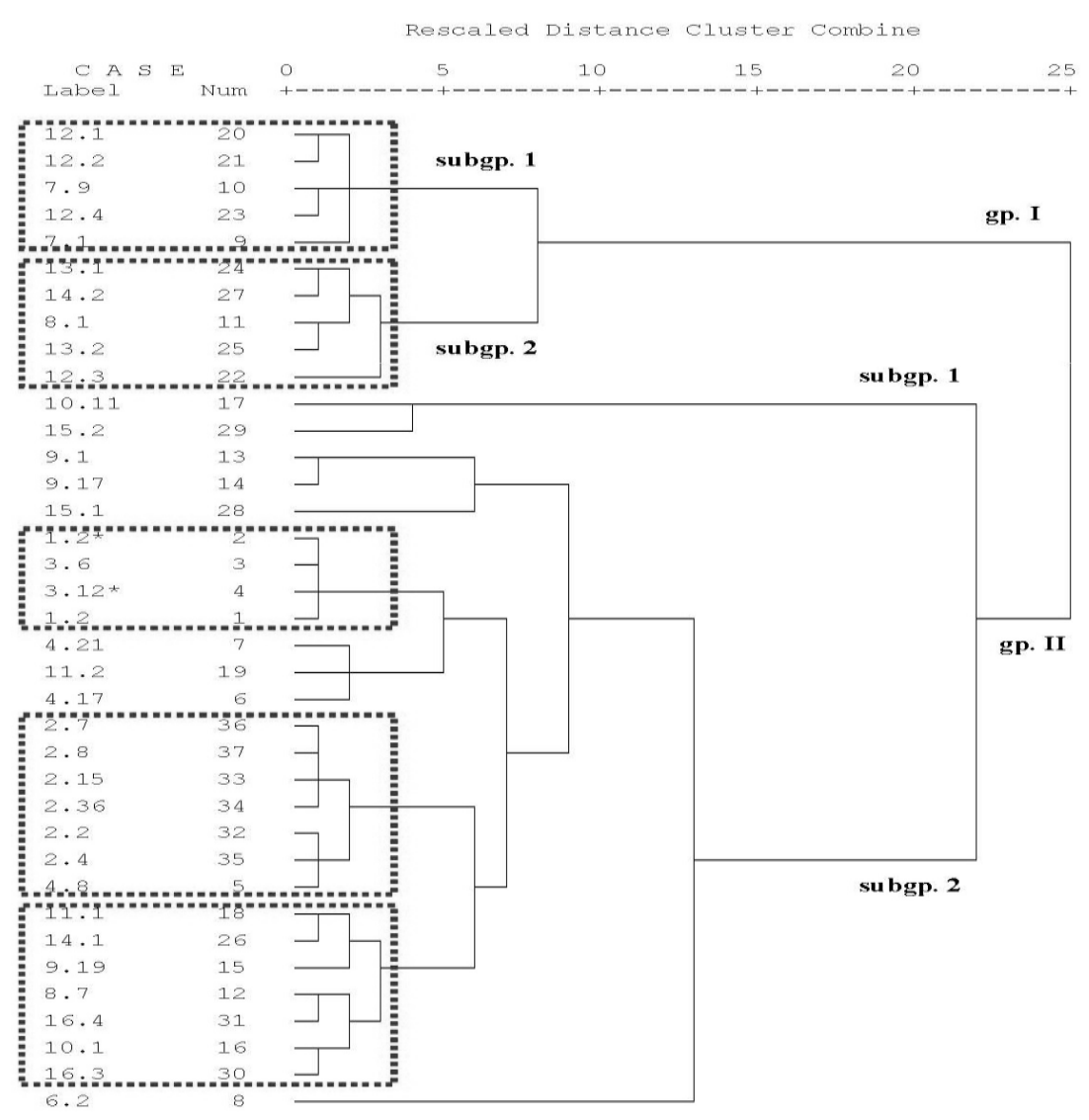

Fig. 2. UPGMA dendrogram of physiological relationships among the rhizobial isolates determined by $\mathrm{NaCl}$ tolerance. Rectangles indicating closely clustered groups (gp.) and/or subgroups (subgp.). 
pH - tolerance

As shown in Fig. 3, the rhizobial isolates showed a wide diversity in their $\mathrm{pH}$ tolerance. All the isolates grew well at $\mathrm{pH} 6.8$ being the control cultures. At $\mathrm{pH} 9$, $89.2 \%$ of the isolates gave high growth while $10.8 \%$ of the isolates gave moderate growth. At $\mathrm{pH} 10,70.3 \%$ and $2.7 \%$ of the isolates showed moderate and low growth, respectively. At $\mathrm{pH} 11,68 \%$ of the isolates gave low growth. $86.5 \%$ and $70.3 \%$ of the isolates were unable to survive at $\mathrm{pH} 4$ and 5, respectively. While, $13.5 \%$ of the isolates gave low growth at $\mathrm{pH} 4$, and $16.2 \%, 5.4 \%$ and $8.1 \%$ of isolates showed low, moderate and high growth at $\mathrm{pH} 5$, respectively.
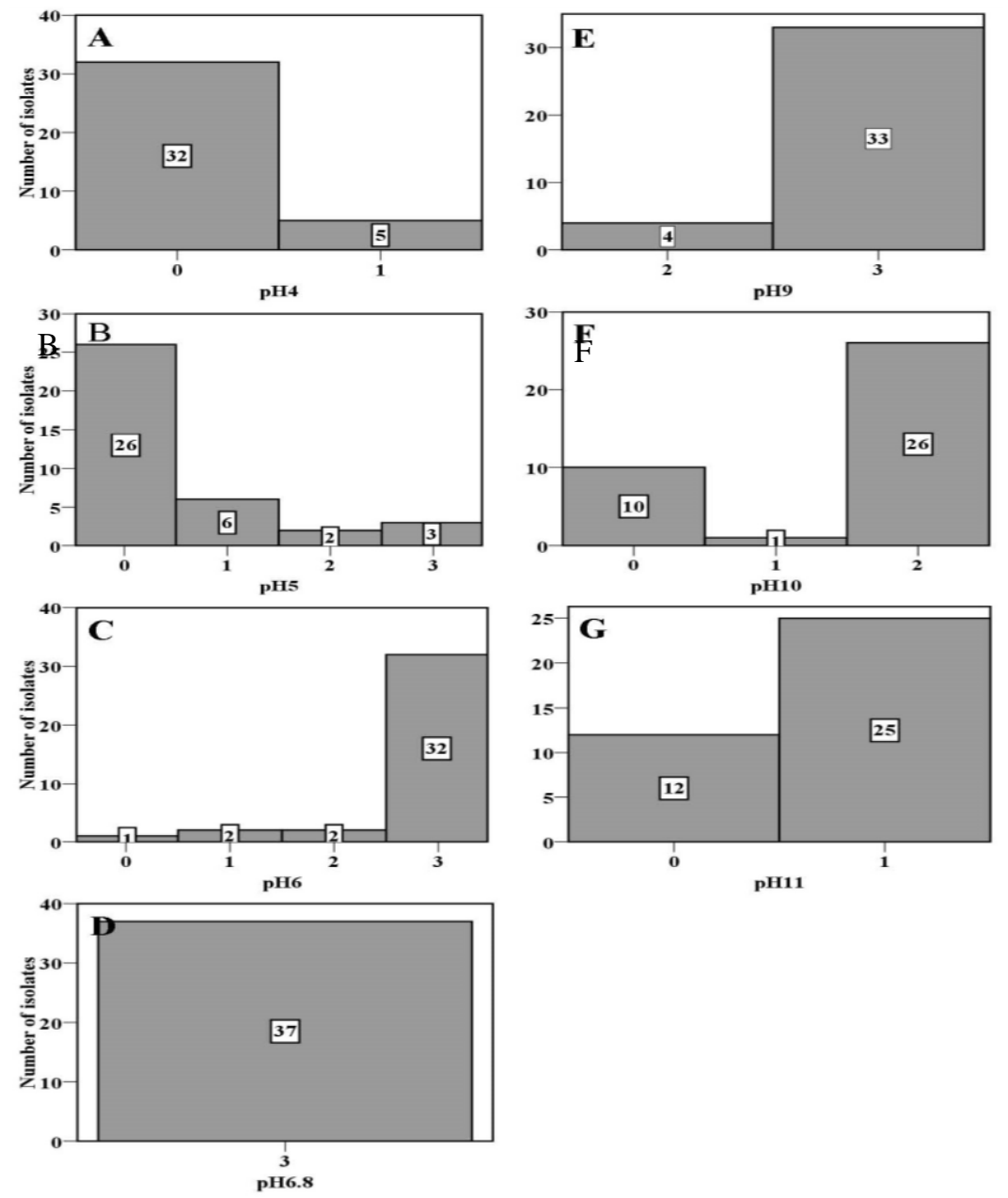

Fig. 3. Frequency distribution of the different isolates showing the effect of different pH.

Egypt. J. Microbiol. 50 (2015) 
Cluster analysis of the rhizobial isolates according to their tolerance to the different pHs showed a diversity among them (Fig. 4). Two isolates (7.9 and 12.4) were clustered separately in group II away from group I. The latter was subdivided into two subgroups, where subgroup 1 comprised of 7 clusters. Cluster 1 include isolates $(2.7,2.8,1.2 *, 2.36,2.4,2.2,2.15,14.2,15.1,7.1,13.2$, 4.8 and 4.17) that had isolates with the same origin and able to grow at $\mathrm{pH}$ values above 6.8 till 11. Cluster 2 comprised of five isolates $(11.2,13.1,10.1,10.11$ and 11.1), that were able to grow at $\mathrm{pH}$ values from 5 to 11 and few of them had the same origin. Cluster 6 comprised of six isolates $(9.19,12.3,3.6,9.1,9.17$ and $3.12^{*}$ ) that had isolates with the same origin (few) and able to grow at $\mathrm{pH}$ values 6, 6.8 and 9 (Fig. 4).

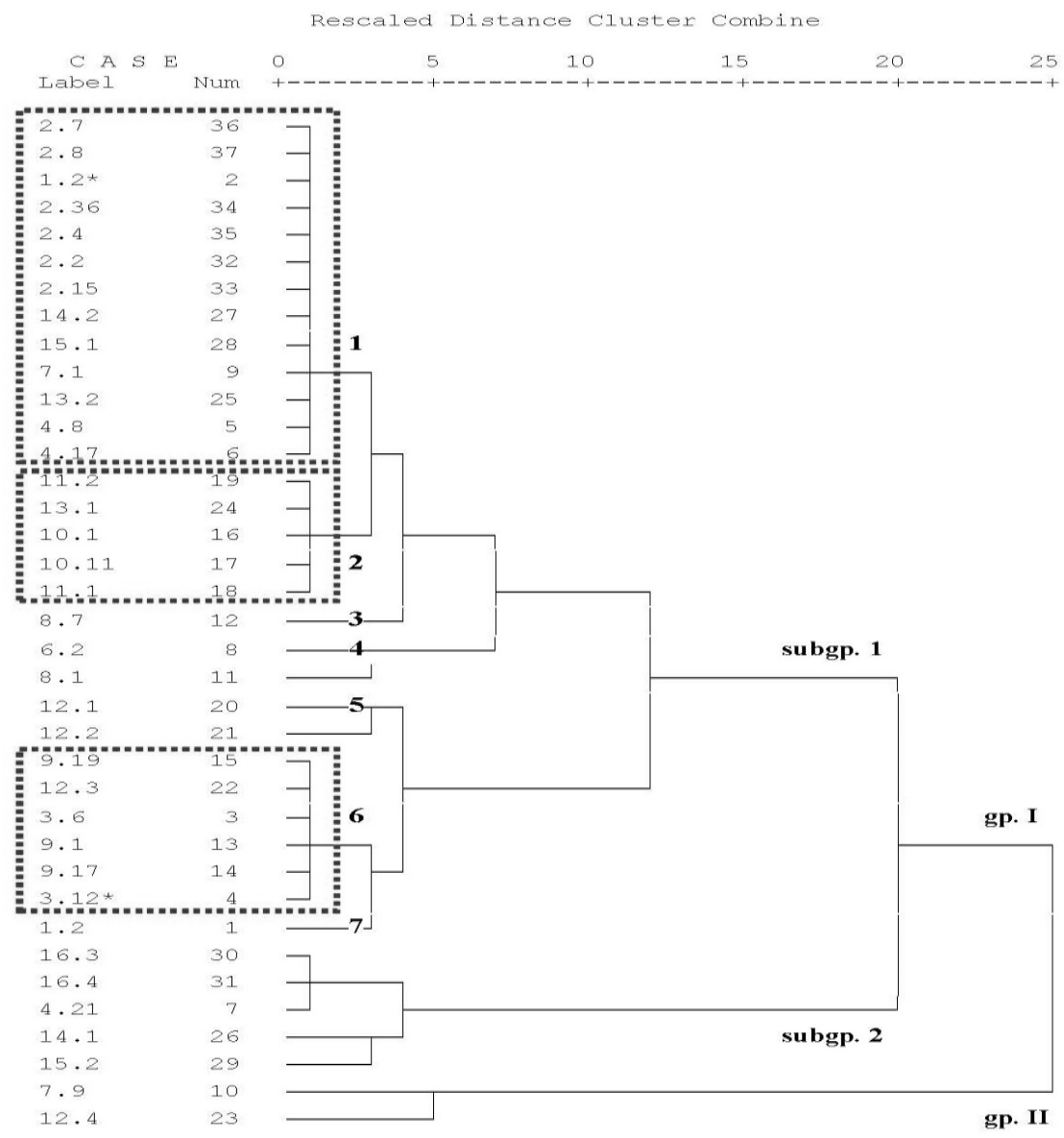

Fig. 4. UPGMA dendrogram of physiological relationships among the rhizobial isolates determined by $\mathrm{pH}$ tolerance. Rectangles indicating closely clustered groups (gp.) and/or subgroups (subgp.). 
Molecular characterization of rhizobial isolates

Genomic DNA was extracted from the 37 rhizobial isolates. This DNA was used as a template for amplification of rep PCR primers (REP, ERIC and BOX). Such PCR products were used to discriminate between the isolates and to obtain a picture about the diversity and the natural variation that might exist between the rhizobial isolates.

PCR amplification with REP and ERIC primers

PCR with REP and ERIC primer pairs of DNA from the isolates yielded multiple distinct DNA products of size ranged from 177 to $3773 \mathrm{bp}$ with the REP primer and from 200 to $2921 \mathrm{bp}$ with the ERIC primer.

High resolution REP and ERIC PCR fingerprints of the 37 isolates were generated. Isolates $(4.8,7.1,10.11,11.1,15.2$ and 16.4) and $(2.7,2.15,3.6,7.1,7.9$, $8.1,8.7,10.11,11.2,13.2$ and 16.4) did not produce a PCR amplification profile with REP and ERIC PCR respectively, while the remaining 31 and 26 isolates were resolved in distinctive profiles with REP and ERIC PCR, respectively.

REP- PCR analysis of the 31 isolates revealed a relatively high level of genetic diversity for isolate 12.2. On the other hand, isolates (3.6, 9.1 and 10.1), (9.19, 14.1 and 14.2;), (2.15 and 4.17) and (2.36, 2.4, 2.7 and 2.8;) showed 100\% homology except 14.2 being $85 \%$ (Fig. 5).

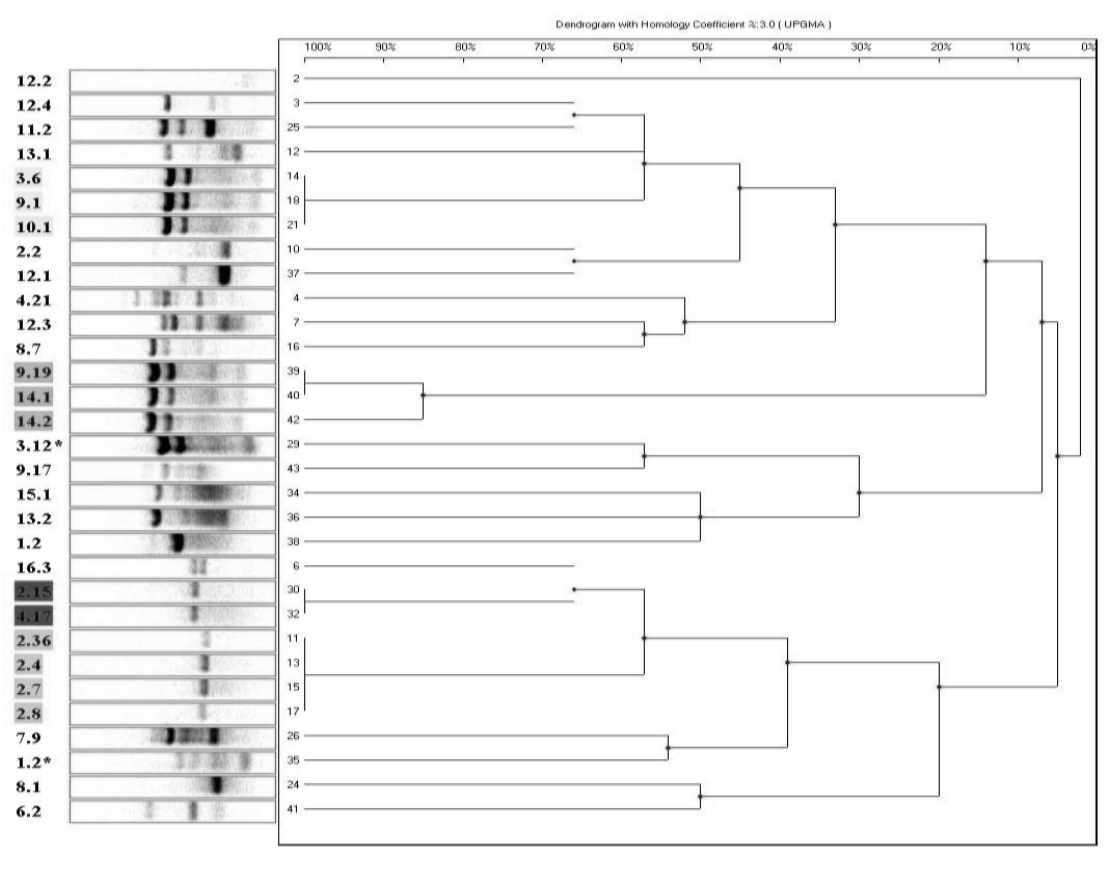

(A)

(B)

Fig. 5. Electrophoretic patterns for the different rhizobial isolates generated by repPCR using REP primer (A). Dendrogram of the 31 rhizobial isolates originated by UPGMA cluster analysis based on REP primer (B).

Egypt. J. Microbiol. 50 (2015) 
ERIC PCR analysis of the 28 rhizobial isolates showed $100 \%$ high similarity between isolates (12.2 and 12.3) and (2.2 and 2.36). While the dendrogram showed isolates $\left(2.8,3.12^{*}, 15.1,1.2,14.1\right)$ that was closely clustered together with percentage of $65 \%$ similarity (Fig. 6).

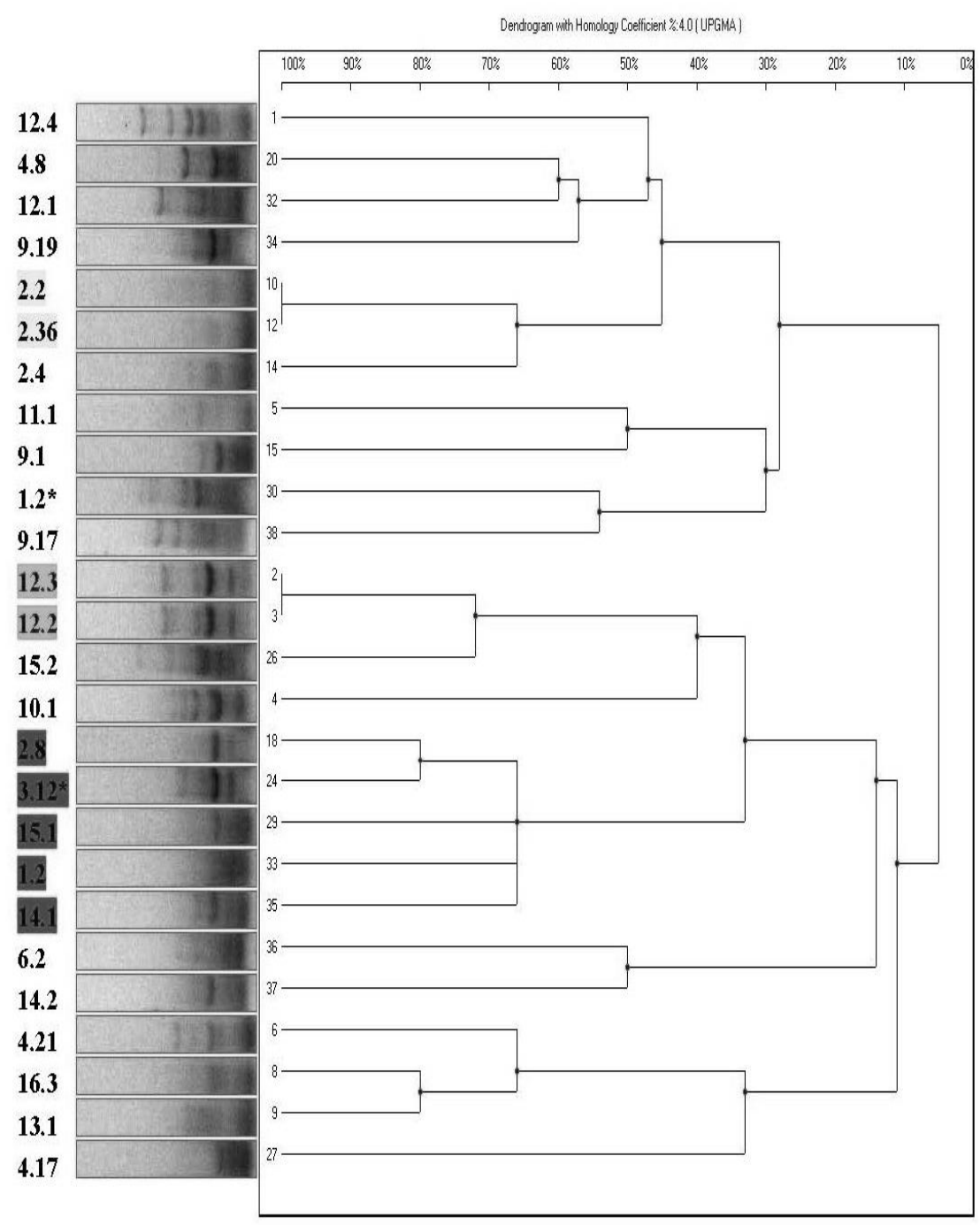

(A)

(B)

Fig. 6. Electrophoretic patterns for the different rhizobial isolates generated by repPCR using ERIC primer (A). Dendrogram of the 28 rhizobial isolates originated by UPGMA cluster analysis based on ERIC primer (B). 
PCR amplification with specific BOX AlR primer

BOX A1R primer did not reveal any polymorphism in all isolates (data not shown).

\section{Discussion}

Colonies of the obtained isolates showed little or no $\mathrm{CR}$ absorption when incubated in dark and grow poorly on peptone glucose agar medium containing BCP. Therefore, it is designated as colonies of a typical Rhizobium species. This judgment coincides with that obtained by others (Deshwal \& Chaubey, 2014 and Somasegaran \& Hoben, 1994).

In this study, the colonies of the 37 rhizobial isolates showed large variation in their morphological traits similar to those obtained by Singh et al. (2008) and Zahran et al. (2012). Regarding the pH-reaction, the 37 rhizobial isolates showed an acid reaction assuming that these isolates are fast-growing rhizobia. In this respect, the obtained results coincide with that obtained by many workers (Baoling et al., 2007; Hatice et al., 2009; Somasegaran \& Hoben, 1994 and Vincent, 1970).

Saline conditions may limit Rhizobium-legume association by affecting survival and proliferation of Rhizobium spp. in soil and rhizosphere; inhibiting the early stages of infection process; affecting root nodule development and reducing the host growth (Evans, 2015 and Graham, 1991). In the present work, most of the rhizobial isolates showed high capacity for salt tolerance as 26 and 5 out of 37 isolates could withstand up to $5 \%$ and $7 \% \mathrm{NaCl}$, respectively. This $\mathrm{NaCl}$ tolerance agreed with previous reports (Abdel-Wahab et al., 2002; AlShaharani \& Sheetta, 2011; Legesse \& Assefa, 2014; Zahran et al., 2003 and Zahran et al., 2012). Nevertheless, other Rhizobium strains from arid saline areas were highly salt-tolerant and withstand high $\mathrm{NaCl}$ levels up to 5-10\% (AbdelWahab et al., 2002 and Zahran et al., 2003).

The dendrogram obtained from the numerical analysis of $\mathrm{NaCl}$ tolerance of the 37 isolates showed a wide diversity among them. Only, few isolates grouped together as they were able to tolerate $\mathrm{NaCl}$ concentration up to $3 \%$ or $5 \%$ and few of them had the same origin.

Extreme $\mathrm{pH}$ can be a major factor limiting fast growing groups. Slight variation in $\mathrm{pH}$ of the medium might have significant effects on the growth of bacteria or organism (Adhikari et al., 2012; Singh et al., 2008 and Yan et al., 2014). In this study, the majority of isolates could tolerate $\mathrm{pH}$ up to 10 , while 25 out of 37 isolates gave poor growth at $\mathrm{pH} 11$. On the other hand, at acidic conditions ( $\mathrm{pH} 4$ and 5), only 5 and 11 isolates could grow, respectively. Such results agreed with studies on rhizobial strains (Guerrouj et al., 2013; Legesse \& Assefa, 2014; Youseif et al., 2014 and Zahran et al., 2012), who showed that even $\mathrm{pH} 10$ was not inhibitory to rhizobial strains and these strains were sensitive to acidic conditions ( $\mathrm{pH} 3.5-4.0)$. 
Both REP- and ERIC-like sequences (elements) are present in the genomes of gram-negative soil bacteria, such as rhizobia (De Bruijn, 1992). In the present work, both REP and ERIC-PCR profiles enabled strain differentiation and demonstrated a considerable degree of genetic diversity among the rhizobial isolates. The isolates were clustered on the bases of fingerprinting similarity where few of them had the same origin. Also, our results support the conclusion of De Bruijn, (1992), Edulamudi et al. (2015) Evans (2015) and Laguerre et al. 1994) that the REP and ERIC PCR could become a powerful tool for the molecular genetic analysis of bacteria and for bacterial taxonomy. It allows the fingerprinting of individual genera, species, and strains and could help to determine phylogenetic relationships. Also, these findings are in agreement with the results obtained by other authors who studied diversity among natural rhizobial populations in different world regions (Adiguzel et al., 2009 and Granada et al., 2014).

It could be concluded that rhizobia isolated from root nodules of $M$. indicus from Egyptian soils are both phenotypically and genetically diverse. Utilization of both salt and $\mathrm{pH}$ tolerant rhizobial isolates may contribute to the reclamation of salt affected soils which occupy large worldwide areas.

\section{References}

Abdel-Salam, M.S., Ibrahim, S.A., Abd-El-Halim, M.M., Badawy, F.M. and AboAba, S.E.M. (2010) Phenotypic characterization of indigenous Egyptian rhizobial strains for abiotic stresses performance. J. Am. Sci. 6, 498-503.

Abdel-Wahab, S.M., El-Bakry, A.A., Tantawy, H. and El-Batanony, N.H. (2002) Phenotypic characterization of some wild rhizobial isolates isolated from some wild legumes in Egypt. El-Azhar J. Microbiol. 58, 87-102.

Adhikari, D., Kaneto, M., Itoh, K., Suyama, K., Pokharel, B.B. and Gaihre, Y.K. (2012) Genetic diversity of soybean-nodulating rhizobia in Nepal in relation to climate and soil properties. Plant Soil, 357,131-145.

Adiguzel, A., Ogutcu, H., Baris, O., Karadayi, M., Medine, G. and Sahin, F. (2009) Isolation and characterization of Rhizobium strains from wild vetch collected from high altitudes in Erzurum-Turkey. Rom Biotechnol Lett. 15, 5017- 5024.

Alikhani, H.A. and Yakhchali, B. (2009) Potential use of Iranian rhizobial strains as plant growth promoting rhizobacteria (PGPR) and effects of selected strains on growth characteristics of wheat, corn and alfalfa. Desert, 14, 27-35.

Al-Shaharani, T.S. and Shetta, N.D. (2011) Evaluation of growth, nodulation and nitrogen fixation of two Acacia species under salt stress. World Appl Sci J.13, 256265 .

Arora, N.K. and Kang, S.C. and Maheshwari, D.K. (2001) Isolation of siderophoreproducing strains of Rhizobium meliloti and their biocontrol potential against Macrophomina phaseolina that causes charcoal rot of groundnut. Curr. Sci. 81, 673677.

Egypt. J.Microbiol. 50 (2015) 
Bala, A. and Giller, K.E. (2006) Relationships between rhizobial diversity and host legume nodulation and nitrogen fixation in tropical ecosystems. Nutr. Cycl Agroecosyst. 76, 319-330.

Baoling, H., Chengqun, L. and Liqin, F. (2007) A rhizobia strain isolated from root nodule of gymnosperm Podocarpus macrophyllus. Sci. Chin. Ser C-Life Sci. 50, 1-6.

Beauregard, M.S., Zheng, W. and Seguin, P. (2004) Diversity of Trifolium ambiguum nodulating rhizobia from the lower Caucasus. Biol. Fertil. Soils, 40, 128-135.

Boulos, L. (2000) "Flora of Egypt". Al-Hadara Publishing Cairo.

De Bruijn, F.J. (1992) Use of repetitive (Repetitive Extragenic Palindromic and Enterobacterial Repetitive Intergeneric Consensus) sequences and the polymerase chain reaction to fingerprint the genomes of Rhizobium meliloti isolates and other soil bacteria. Appl. Environ. Microb. 58, 2180-2187.

Deshwal, V.K. and Chaubey, A. (2014) Isolation and characterization of Rhizobium leguminosarum from root nodule of Pisum sativum L. JAIR, 2, 464- 467.

Drew, E.A. and Ballard, R.A. (2010) Improving $\mathrm{N}_{2}$ fixation from the plant down: Compatibility of Trifolium subterraneum L. cultivars with soil rhizobia can influence symbiotic performance. Plant Soil, 327, 261-277.

Edulamudi, P., Masilamani, A.J.A., Divi, V.R.S.G., Zakkula, V. and Konada, V.M. (2015) Genetic characterization of rhizobia associated with horse gram [Macrotyloma uniflorum (Lam.) Verdc.] based on RAPD and RFLP. Br. Microbiol. Res. J. 5, 340350 .

Evans, A.T. (2015) Phylogeny and diversity of rhizobial bacteria. J. Phylogen. Evolution Biol. 3,1.

Gálvez, M.D. (2005) Nodule metabolism in Pisum sativum L. in response to water stress: carbon/nitrogen interactions and the possible molecules involved in the modulation of the response, Ph.D. Thesis, Public University of Navarre.

Graham, P.H. (1991) Stress tolerance in Rhizobium and Bradyrhizobium and nodulation under adverse soil conditions. Can. J. Microb. 38, 475-484.

Granada, C.E., Strochein, M., Vargas, L.K., Bruxel, M., Saccol de Sá, E.l. and Passaglia, L.M.P. (2014) Genetic diversity and symbiotic compatibility among rhizobial strains and Desmodium incanum and Lotus spp. Plants. Genet. Mol. Biol. 37, 396-405.

Guerrouj, K., Pe'rez-Valera, E., Chahboune, R., Abdelmoumen, H., Bedmar, E.J. and El Idrissi, M.M. (2013) Identification of the rhizobial symbiont of Astragalus glombiformis in Eastern Morocco as Mesorhizobium camelthorni. Antonie van Leeuwenhoek, 104,187-198. 
Hatice, O., Ahmed, A., Medine, G., Mehmet, K. and Fikrettin, S. (2009) Molecular characterization of Rhizobium strains isolated from wild Chickpeas collected from high altitudes in Erzurum-Turkey. Rom. Biotechnol . Lett. 14, 4294-4300.

Kaschuk, G., Hungria, M., Santos, J.C.P. and Berton-Junior, J.F. (2006) Differences in common bean rhizobial populations associated with soil tillage management in southern Brazil. Soil Tillage Res. 87, 205-217.

Kesari, V., Ramesh, A.M. and Rangan, L. (2013) Rhizobium pongamiae sp. nov. from root nodules of Pongamia pinnata. Biomed Res Int. 1-9.

Koornneef, M., Alonso-Blanco, C. and Vreugdenhil, D. (2004) Naturally occurring genetic variation in Arabidopsis thaliana. Annu. Rev.Plant .Biol. 55, 141 - 172.

Laguerre, G., Allard, M., Revoy, F. and Amarger, N. (1994) Rapid identification of rhizobia by restriction fragment length polymorphism analysis of PCR-amplified $16 \mathrm{~S}$ rRNA genes. Appl. Environ. Microb. 60, 56-63.

Legesse, S. and Assefa, F. (2014) Symbiotic and phenotypic characteristics of rhizobia nodulating faba bean (Vicia Faba) from Tahtay Koraro, northwestern zone of Tigray Regional State, Ethiopia. Int. J. Emerg. Eng. Res. Technol. 2, 15-23.

Shamseldin, A.A.Y., Vinuesa, P., Thierfelder, H. and Werner, D. (2005) Rhizobium etli and Rhizobium gallicum nodulate Phaseolus vulgaris in Egyptian soils and display cultivar-dependent symbiotic efficiency. Symbiosis, 38, 145-161.

Shetta, N.D., Al-Shaharan, I.T.S. and Abdel-Aal, M. (2011) Identification and characterization of Rhizobium associated with woody legume trees grown under Saudi Arabia condition. Am. J. Agric. Environ. Sci. 10(3) 410-418.

Singh, B., Kaur, R. and Singh, K. (2008) Characterization of Rhizobium strain isolated from the root of Trigonella foenum graecum (fenugreek). Afr. J. Biotechnol. 7, 36713676.

Somasegaran, P. and Hoben, H.J. (1994) "Handbook for Rhizobia", Springer-Verlag, New York, USA.

Stewart, C.N. and Via, L.E. (1993) A rapid CTAB DNA isolation technique useful for RAPD fingerprinting and other PCR applications. Biotechniques, 14, 748-750.

Täckholm, V. (1974) "Student's Flora of Egypt”, Cooperative Printing, Beirut, $2^{\text {nd }}$ ed. Cairo University, Cairo.

Velázquez, E., García-Fraile, P., Ramírez-Bahena, M. H., Peix, A. and Rivas, R. (2010) In: "Proteobacteria Forming Nitrogen Fixing Symbiosis with Higher Plants. Proteobacteria: Phylogeny, Metabolic Diversity and Ecological Effects”. Sezenna, M.L. (Ed.), pp. 37-56. Nova Science Publishers Inc., New York, USA,

Versalovic, J., Schneider, M., De Bruijn, F.J. and Lupski, J.R. (1994) Genomic fingerprinting of bacteria using repetitive sequence-based polymerase chain reaction. Meth. Mol. Cell Biology, 5, 25-40. 
Vincent, J.M. (1970) "A Manual for the Practical Study of the Root Nodule Bacteria". IBP15. Blackwell Scientific Publications. Oxford and Edinburgh. U. K.

Yan, J., Han, X.Z., Ji, Z.J., Li, Y., Wang, E.T., Xie, Z.H. and Chen, W.F. (2014) Abundance and diversity of soybean-nodulating rhizobia in black soil are impacted by land use and crop management. App1. Environ. Microbial. 80, 5394-5402.

Youseif, S.H., Abd El-Megeed, F.H., Ageez, A., Zeinat, K., Mohamed, Z.K., Shamseldin, A. and Saleh, S. A. (2014) Phenotypic characteristics and genetic diversity of rhizobia nodulating soybean in Egyptian soils. Eur . J. Soil. Biol. 60, 3443.

Zahran, H.H. (1999) Rhizobium-legume symbiosis and nitrogen fixation under severe conditions and in an arid climate. Microbiol. Mol. Biol. Rev. 63, 968-989.

Zahran, H.H., Abdel-Fattah, M., Ahmad, M.S. and Zaki, A.Y. (2003) Polyphasic taxonomy of symbiotic rhizobia from wild leguminous plants growing in Egypt. Folia. Microbiol. 348, 510-520.

Zahran, H.H., Abdel-Fattah, M., Yasser, M.M., Mahmoud, A.M. and Bedmar, E.J. (2012) Diversity and environmental stress responses of rhizobial bacteria from Egyptian grain legumes. Aust. J. Basic Appl. Sci. 6, 571-583.

(Received 24 /6/2015; accepted $6 / 9 / 2015)$ 


\section{تنوع الريزوبيا المعزولة من نبات الحندقوق المر في الأراضي}

نادية حامد البتانوني، آيات مصطفي بدوي"، حسن الطنطاوي حسن ومحمد عزت

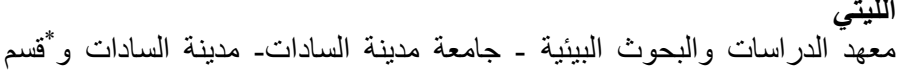
النباتـ كلية العلوم- جامعة المنوفية ــ المنوفية ــ مصر.

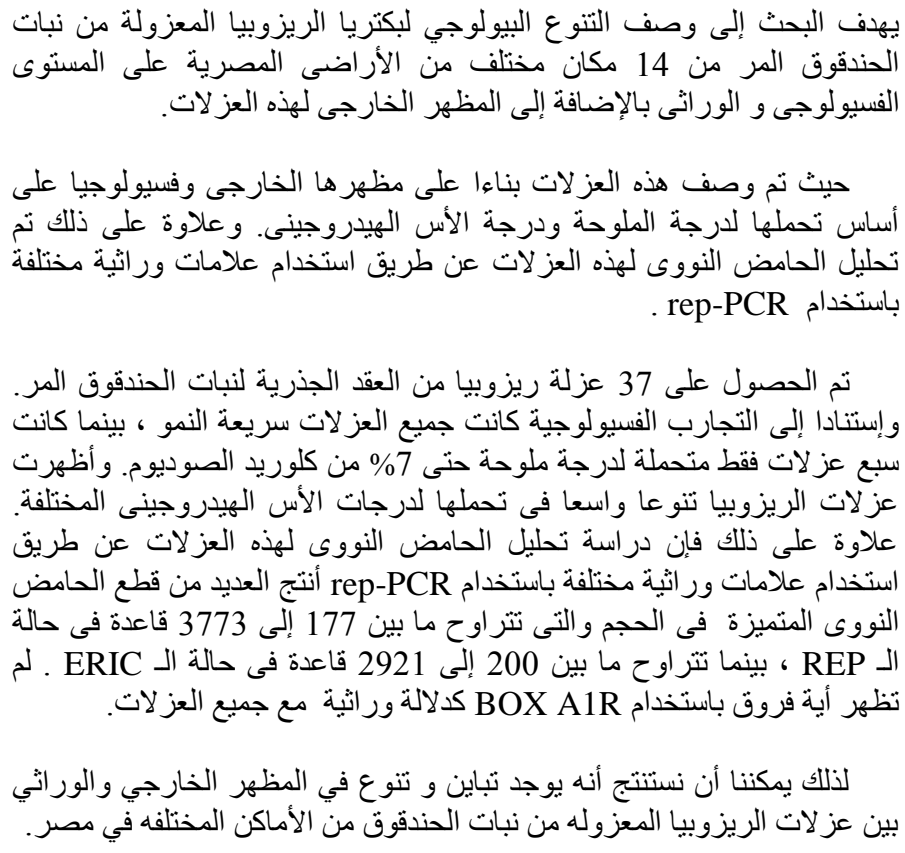

